\title{
SOME CLINICAL NOTES AND ELECTROENCEPHALOGRAPHIC FINDINGS IN CEREBRAL PALSY
}

\author{
BY \\ GRACE E. WOODS* \\ From the Cerebral Palsy Assessment Clinic, Children's Hospital, Bristol
}

(RECEIVED FOR PUBLICATION NOVEMBER 13, 1964)

During the past 10 years, electroencephalographic recordings have been taken on children with cerebral palsy, who were attending a special clinic at the Royal Hospital for Sick Children, Bristol. In this paper an attempt has been made to evaluate these records and, in particular, to assess their importance to the clinician.

The published findings on the electroencephalogram (EEG) in cerebral palsy are not extensive possibly because of the difficulty in obtaining records from these severely handicapped children. An early survey was made by Perlstein, Gibbs, and Gibbs (1946). Aird and Cohen (1950) found that $85 \%$ of spastics and $60 \%$ of athetoids gave abnormal records, but that there was focal pathology in only $32 \%$ of athetoids. They suggest that if the EEG shows no evidence of epileptiform disturbance, the chance of a fit occurring is only 1 in 8 . They found no correlation between an abnormal EEG and the intelligence quotient.

Pampiglione (1958) reviewing the literature says that there is considerable agreement on four points: (a) asymmetry between the records from the two hemispheres is commoner in hemiplegia, (b) EEG abnormalities are recognizable in most cerebral palsy patients who have seizures, (c) one-third of the cases show normal records, and this is commoner with athetoids than with spastics, (d) there is a smaller proportion of abnormal EEGs among patients whose condition is ascribed to prematurity or anoxia than in those who have a known cerebral injury or infection.

Denhoff and Robinault (1960) found that $24 \%$ of a group of 95 cerebral-palsied children had normal records. Lundervold (1960) compared air-encephalographic and electroencephalographic findings and showed that the combined results had some prognostic significance.

\footnotetext{
* Present address: St. Ebba's Hospital, Epsom, Surrey.
}

Melin (1962) stressed the importance of serial EEG examinations and stated that 80 to $85 \%$ of cerebralpalsied children with a history of convulsive disorders showed an abnormal EEG. He particularly mentioned the cases where the EEG findings predicted a future convulsive disorder, and recommended close supervision of the patient and possibly prophylactic anticonvulsant therapy.

Jabbour and Lundervold (1963) obtained EEG records on 43 hemiplegic children. They found that epilepsy occurred in equal proportions among those with normal or near normal records, and those with severely abnormal records. But the follow-up showed better control of the epilepsy in children with more nearly normal records. His records appear to have been taken in very young children.

Lesny (1963) investigated cerebellar disorders in childhood and stated that a 'synchronous bioccipito-temporal slow wave activity inhibited by eye-opening' was a fairly common finding. Ounsted (1963) made EEG studies of 20 children with cerebellar disease and found 7 with normal records, and varying abnormalities in the remainder.

\section{Present Findings}

In reporting the present series of EEG findings, the patients are analysed in rather arbitrary groups according to the major movement handicap of the child. Records were obtained on the majority of patients with cerebral palsy who were being supervised and treated in the clinic. Usually an EEG record was obtained once in early childhood at about the age of 3 years, and again during school life. In patients with epilepsy more frequent records were taken.

Athetosis. In this group of cases 62 records were obtained from 35 patients under the age of 16 years. All showed athetosis. In a few patients there was 
TABLE 1

ANALYSIS OF EEG RECORDS IN INDIVIDUAL CASES OF ATHETOSIS

\begin{tabular}{|c|c|c|c|c|c|c|c|}
\hline Name & EEG & Aetiology & $\begin{array}{c}\text { Birth Weight } \\
\text { (g.) }\end{array}$ & IQ & Severity & Remarks & $\begin{array}{l}\text { No. of } \\
\text { Records }\end{array}$ \\
\hline $\begin{array}{l}\text { A.B. } \\
\text { R.H. } \\
\text { M.B. } \\
\text { C.E. } \\
\text { B.A. } \\
\text { J.C. } \\
\text { J.B. } \\
\text { J.W. } \\
\text { D.K. } \\
\text { J.H. } \\
\text { A.H. } \\
\text { M.P. } \\
\text { R.P. } \\
\text { V.T. } \\
\text { F.G. } \\
\text { D.H. } \\
\text { R.R. } \\
\text { A.P. } \\
\text { J.B. } \\
\text { R.F. } \\
\text { M.R. } \\
\text { P.L. } \\
\text { A.B. } \\
\text { S.H. } \\
\text { C.T. } \\
\text { T.S. } \\
\text { T.C. } \\
\text { S.T. } \\
\text { M.L. } \\
\text { S.M. } \\
\text { G.H. } \\
\text { F.B. } \\
\text { J.S. } \\
\text { D.H. } \\
\text { M.C. }\end{array}$ & 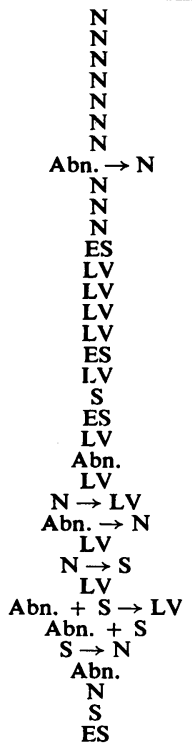 & $\begin{array}{c}\text { Asph. } \\
\text { Asph. } \\
\text { Asph. } \\
\text { ? } \\
\text { ? } \\
\text { Rh. jaund. } \\
\text { ? } \\
\text { Jaund. } \\
\text { Rh. jaund. } \\
\text { Jaund. } \\
\text { R. jaund. } \\
\text { Jaund. } \\
\text { Jaund. } \\
\text { Jaund. } \\
\text { Jaund. } \\
\text { Rh. jaund. } \\
\text { Jaund. } \\
\text { Rh. jaund. } \\
\text { Asph. } \\
\text { ? } \\
\text { Asph. } \\
\text { Asph. } \\
\text { Jaund. } \\
\text { ? } \\
\text { Asph. } \\
\text { Asph. } \\
\text { ? } \\
\text { Jaund. } \\
\text { Asph. } \\
\text { Asph. } \\
\text { Asph. } \\
\text { Asph. + jaund. } \\
\text { ? } \\
\text { Asph. } \\
\text { Asph. + jaund. }\end{array}$ & $\begin{array}{l}3,175 \\
1,814 \\
3,628 \\
3,061 \\
1,360 \\
2,635 \\
3,571 \\
1,870 \\
2,267 \\
2,267 \\
2,267 \\
1,587 \\
2,578 \\
2,437 \\
1,360 \\
2,041 \\
3,175 \\
3,770 \\
1,671 \\
3,402 \\
1,927 \\
1,615 \\
2,125 \\
3,117 \\
3,798 \\
2,607 \\
1,814 \\
1,814 \\
2,493 \\
2,834 \\
2,948 \\
2,976 \\
1,785 \\
2,891 \\
2,749\end{array}$ & $\begin{array}{c}120+ \\
\text { Average } \\
\text { Average } \\
\text { Average } \\
\text { ESN } \\
\text { Average } \\
\text { ESN } \\
\text { Average } \\
\text { Average } \\
\text { Average } \\
\text { Average } \\
\text { Average } \\
\text { Average } \\
\text { Average } \\
\text { ESN } \\
\text { Average } \\
\text { Average } \\
\text { Ineduc. } \\
\text { ? ESN } \\
\text { Ineduc. } \\
\text { Average } \\
\text { Ineduc. } \\
\text { ESN } \\
\text { Average } \\
\text { Univ. 140 + } \\
\text { Ineduc. } \\
\text { 120 + } \\
\text { Average } \\
\text { ESN } \\
\text { Average } \\
\text { Average } \\
\text { Average } \\
\text { Average } \\
\text { Average } \\
\text { ESN }\end{array}$ & $\begin{array}{l}\text { Mod. } \\
\text { Mild } \\
\text { Mild } \\
\text { Mild } \\
\text { Mod. } \\
\text { Mild } \\
\text { Mild } \\
\text { Mild } \\
\text { Mod. } \\
\text { Severe } \\
\text { Mod. } \\
\text { Mod. } \\
\text { Mod. } \\
\text { Severe } \\
\text { Severe } \\
\text { Mod. } \\
\text { Mild } \\
\text { Severe } \\
\text { Severe } \\
\text { Mod. } \\
\text { Mild } \\
\text { Mod. } \\
\text { Severe } \\
\text { Severe } \\
\text { Mild } \\
\text { Severe } \\
\text { Mod. } \\
\text { Severe } \\
\text { Severe } \\
\text { Severe } \\
\text { Severe } \\
\text { Mod. } \\
\text { Mod. } \\
\text { Severe } \\
\text { Severe }\end{array}$ & $\begin{array}{c}\text { Deaf } \\
\text { Deaf: } \boldsymbol{P} \text {. } m a l . \\
\text { Beaf } \\
\text { Deaf } \\
\text { Deaf } \\
\text { Deaf } \\
\text { Deaf } \\
\text { Deaf } \\
\text { Deaf } \\
\text { Deaf } \\
\text { Deaf } \\
\text { Epileptic } \\
\\
\text { Epileptic } \\
\text { Deteriorating } \\
\text { Epileptic } \\
\text { Deaf } \\
\text { Deaf } \\
\\
\text { Deaf } \\
\text { Deaf }\end{array}$ & $\begin{array}{l}1 \\
1 \\
1 \\
3 \\
1 \\
1 \\
1 \\
2 \\
3 \\
1 \\
1 \\
1 \\
2 \\
2 \\
1 \\
2 \\
3 \\
1 \\
1 \\
1 \\
2 \\
1 \\
1 \\
3 \\
1 \\
1 \\
2 \\
2 \\
4 \\
1 \\
7 \\
1 \\
2 \\
3 \\
1\end{array}$ \\
\hline
\end{tabular}

$\mathbf{N}=$ normal; Abn. = abnormal $; \mathbf{L V}=$ low voltage $; \mathbf{E S}=$ electric silent $; \mathbf{S}=$ spikes; Asph. = neonatal asphyxia; Jaund. = neonatal jaundice; $\mathrm{ESN}=$ educationally subnormal.

super-added spasticity. The patients were designated mild, moderate, or severe on a functional basis. The mild patients ( 9 in number) had fitted into normal school in spite of incoordinated hand movements. The moderate ones (12 in number), though attending a special school, were thought likely to be fit for some gainful employment in later years and were able to attend to their bodily needs. The severe ones (14 in number) needed help with feeding and other necessary functions, and had little control over hand movements.

The aetiology was fairly clearly divided between 14 patients where it followed neonatal asphyxia, and 14 that followed neonatal jaundice. In the 7 with no history of either condition, 3 had been very immature. In all, 18 were premature. 15 patients showed mild to severe high frequency hearing loss. Three had infrequent grand mal fits and one had petit mal attacks. The EEG findings are analysed in Table 1.

Of particular interest in athetosis are the number of cases, 14 in all, that repeatedly gave low voltage or electrically silent records. This was reported altogether in 21 records, and suggests that this is a likely EEG finding in patients where the damage is presumed to be in the basal ganglia. Of these 14 patients, 7 were deaf, 8 had been premature, and 8 were severely affected. All 14 were very handicapped physically. This finding does not appear to have been emphasized in published reports, possibly because of the difficulty in obtaining records in severe cases of athetosis (Fig. 1).

Of the 11 children with normal records, 5 were mildly affected and 5 moderately affected, 8 were of good average intelligence, and 1 at least was of Grammar School ability. Of the 4 children where a change occurred to a later normal record, 2 were severely affected. Both showed right-sided spikes in earlier records, though neither were epileptic. One record that changed to normal was taken from a mildly affected boy who is now at University. As these children grew older there was a normal development of alpha rhythm which was physically responsive.

Some children showed runs of theta rhythm, frequently of low potential, which might suggest an involvement of deeper structure.

Of the 4 clinical epileptics, one showed a normal record, one a mildly abnormal one, one was a silent record, and only one showed spikes suggesting an epileptic disturbance. These findings only illustrate trends, and some EEG findings were surprising, as is true in all cases of brain pathology. Of the normal 


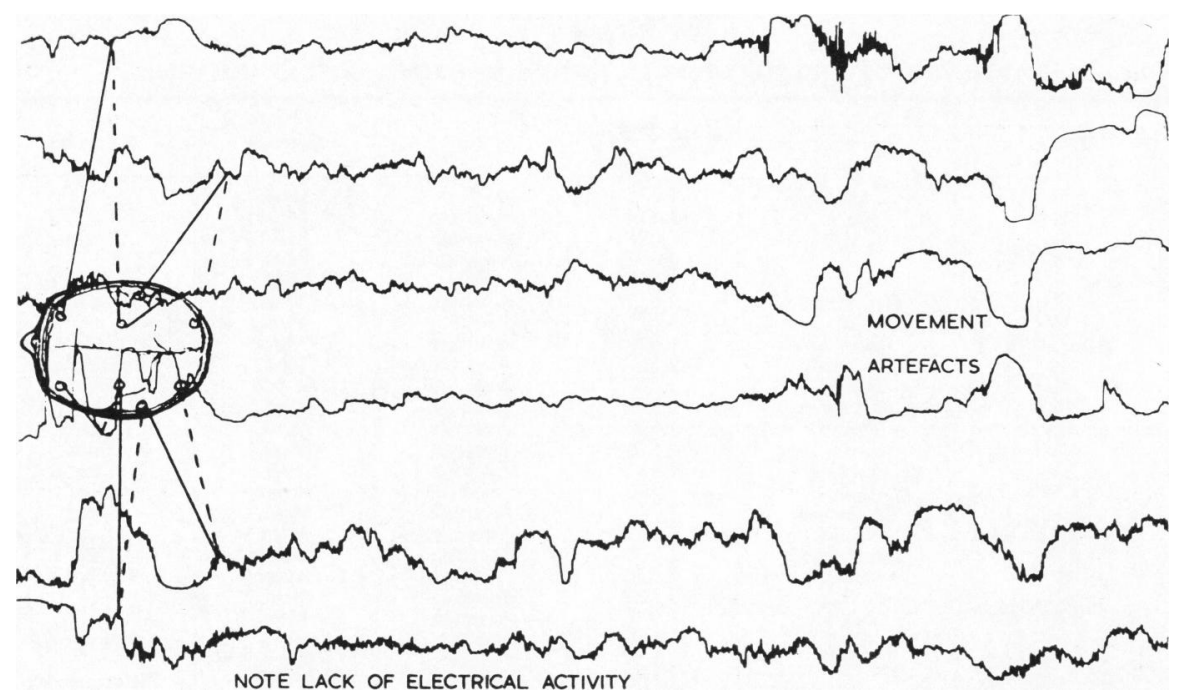

FIG. 1.- Recording of an athetoid patient aged $6 \frac{1}{2}$ years, showing low potential in all regions. The swings in the recording are due to movement artefacts.

records, 3 were found in severely physically affected patients, but in all patients with low voltage records the child was very handicapped physically. All the children had been given a prolonged educational trial and only 4 were considered ineducable, and these 4 had very abnormal records.

Hemiplegia. There were 200 records taken of 100 children. These were representative of the various types of hemiplegic children and include cases of severe mental subnormality and some of above average intelligence. There were 61 right and 39 left hemiplegias. In 72 patients the condition appeared to date from birth, and may have been due to cerebral trauma in the perinatal period. In 28 there was a clear history of postnatal cerebral trauma, infection, or ill-defined illness as the cause of the hemiplegia. As there is a high incidence of epilepsy in hemiplegia, the EEG records are of clinical importance. Of these children $41 \%$ (27 right and 14 left) were epileptic, having had either a solitary or occasional fit, or more frequent attacks. There were $12(42 \cdot 8 \%)$ epileptic patients in the acquired group of 28 hemiplegias, and $29(40.3 \%)$ in the remaining 72 , showing no difference in the incidence of epilepsy between the acquired and congenital cases.

Of the 100 patients, 14 showed persistently normal records. In 10 of these, the children were of good average or above average intelligence. In one boy there was a history of three fits at intervals, but three normal EEG records were obtained. In another boy with a recurring normal record there was an airencephalographic finding of severe cerebral atrophy on the suspected side. The boy had an IQ of 80 and no history of fits up to the age of 17 years. Presumably one normal hemisphere was responsible for a normal EEG. In a few cases a normal record in early childhood was followed by a record during school-life showing mild abnormality. These mild changes appeared to be associated with increasing age and had no clinical significance or prognosis. It is wondered if the high incidence of normal records in Lundervold's series (1960) might not be related to the young age of her cases.

In 5 patients the records became more abnormal and were associated with clinical and educational deterioration. In 2 boys, the hemiplegic condition had been caused by a cerebral-vascular incident associated with Fallot's tetralogy. In one girl, the condition had followed tuberculous meningitis, and the deterioration of the EEG record coincided with $\mathrm{x}$-ray evidence of intracerebral calcification. In another girl the deterioration in the EEG was reported at the same time as an increased incidence of epilepsy and a school report of unexpectedly poor performance, and a drop in IQ from 117 to 87 . An air-encephalogram showed cerebral atrophy of the expected side. In a fifth case the girl had a progressive condition.

Three children produced a normal record after one reported as abnormal. It showed normal maturation of alpha rhythm. This was associated with complete control of fits in 2 patients.

The records were not a completely reliable indication of the side of the lesion. In some cases the abnormalities in the EEG were diffuse, and there 
TABLE 2

RELATION BETWEEN INTELLIGENCE AND ONSET OF FITS

\begin{tabular}{|c|c|c|c|c|}
\hline $\begin{array}{c}\text { Intelligence } \\
\text { Rating }\end{array}$ & Normal & $\begin{array}{l}\text { Educa- } \\
\text { tionally } \\
\text { Sub- } \\
\text { normal }\end{array}$ & $\begin{array}{l}\text { Inedu- } \\
\text { cable }\end{array}$ & Total \\
\hline $\begin{array}{l}\text { No epilepsy } \\
\text { Epilepsy before } 3 \text { years } \ldots \\
\text { Epilepsy after } 3 \text { years } \ldots\end{array}$ & $\begin{array}{l}63 \\
12 \\
14\end{array}$ & $\begin{array}{r}8 \\
11 \\
5\end{array}$ & $\begin{array}{r}6 \\
17 \\
2\end{array}$ & $\begin{array}{l}77 \\
40 \\
21\end{array}$ \\
\hline Total $\quad \ldots$ & 89 & 24 & 25 & $\begin{array}{c}138 \\
\text { (3 too } \\
\text { young) }\end{array}$ \\
\hline
\end{tabular}

were no focal abnormalities. In 6 the EEG recorded a focal abnormality on the ipsilateral side of the movement handicap: 5 of these were epileptic and 5 of low intelligence; and it is possible that the damage in one hemisphere was responsible for the hemiplegia and in the other for the epilepsy. In two patients the air-encephalogram finding supported this view. In 12 , asymmetry between the two hemispheres, taking the form of a low voltage record from the affected hemisphere, was recorded. In some the whole hemisphere was involved and in others the low potential records were focal. In 6 patients the affected hemisphere was silent. These 6 were associated with epilepsy, not easily controlled, and in 5 with severe mental subnormality. A generalized low potential record was obtained in a few patients (Fig. 2a, b) being similar to findings in other types of cerebral palsy.

The EEG records were not a definite indication as to whether clinical epilepsy was occurring. In 40 out of 41 patients with epilepsy, the records were abnormal, and in 29 spikes were recorded. The other records were not specifically epileptic but showed abnormalities such as asymmetry; low potential records, runs of focal delta and theta rhythm, and prolonged following response to photic stimulation. There is a correlation between an abnormal EEG and epilepsy. There is an additional correlation between epilepsy and lowered intelligence, as shown in Table 2, taken from a slightly larger group of 138 cases (Woods, 1963), suggesting that all three factors are evidence of more pronounced brain damage. In 5 patients a wave and spike discharge was recorded but in only one boy was there evidence of petit mal attacks.

In 15 patients, spikes were reported and epilepsy predicted where there was a clear negative history of epilepsy. In 9 children, epilepsy occurred later. The fact that the epileptic record was known to the clinician led to rapid institution of anti-convulsant treatment. Six never developed epilepsy and five have been followed to adult life. This raises the
TABLE 3

ANALYSIS OF EEG RECORDS IN HEMIPLEGIA

\begin{tabular}{|c|c|c|c|c|}
\hline \multicolumn{3}{|c|}{ EEG Findings } & \multirow{2}{*}{\begin{tabular}{|c|}
$\begin{array}{c}\text { Right } \\
\text { Hemiplegia }\end{array}$ \\
9 \\
4 \\
6 \\
7 \\
3 \\
2 \\
6 \\
10 \\
8 \\
\end{tabular}} & 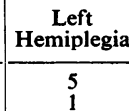 \\
\hline $\begin{array}{l}\text { Normal } \\
\text { Abnormal } \rightarrow \text { normai } \\
\text { Normal } \rightarrow \text { abnormal } \\
\text { Left-sided spikes } \\
\text { Right-sided spikes } \\
\text { Wave and spike } \\
\text { Diffuse spikes } \\
\text { Low voltage ... } \\
\text { Abnormal record } \\
\begin{array}{l}\text { Asymmetry only (affe } \\
\text { quiescent or electri }\end{array}\end{array}$ & $\begin{array}{l}\because \\
\because \\
\therefore\end{array}$ & 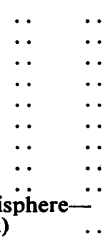 & & \begin{tabular}{r|}
5 \\
1 \\
3 \\
1 \\
11 \\
3 \\
0 \\
2 \\
10 \\
3
\end{tabular} \\
\hline & & & 63 & 39 \\
\hline
\end{tabular}

question as to whether, following an epileptic record, mild anti-epileptic therapy should be instituted as a routine. This has been carried out in 2 patients with marked improvement in the EEG and no occurrence of fits. In this series there were no patients showing aggressive disturbances associated with a temporal lobe focus (Table 3).

Spastic Diplegia. In this series of 50 patients who are variously called spastic paraplegics, spastic diplegics, spastic quadriplegics, and bilateral hemiplegics, there are a mixed group of patients with varying aetiology, severity of handicap, and intelligence range. However, some of them fall into fairly clear-cut aetiological and clinical groups.

Diplegia of Prematurity. One group are patients with symmetrical or near symmetrical spasticity, with lower limbs more affected than upper limbs, the condition following a very premature birth. These can be divided into two grades: (1) where from a functional angle the disability only occurs in the legs and the child has normal control of hands and arms, though neurologically there may be minimal evidence of increased tone and reflexes; and (2) where the upper limbs are functionally affected and the clinical condition of the child is worse. This group of spastic cases has the best prognosis for training and education and forms the bulk of the cases of severe spasticity, able to attend a special school for cerebral palsy.

In the first grade (1) there were 24 patients, and 34 electroencephalographic records were obtained: 13 had normal records and 2 were doubtful. All 13 were of good intelligence (one had an IQ of 140). Three showed evidence of visuo-perceptual difficulties which have been described in these children. One boy, who weighed $2 \mathrm{lb}$. $(908 \mathrm{~g}$.) at birth, showed these learning difficulties to a marked extent and had four normal records over a period of four years.

Of the remaining 9 patients who had abnormal 

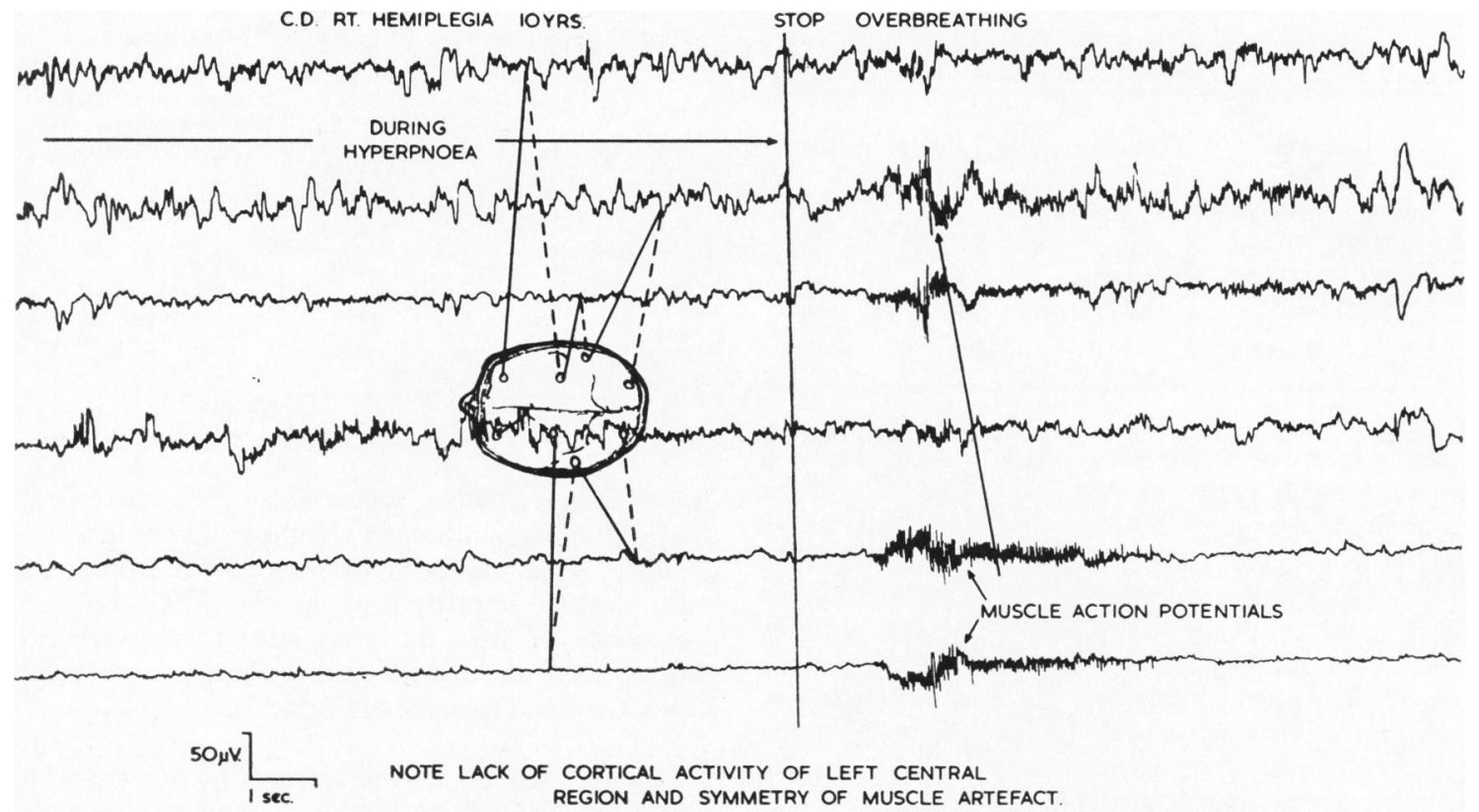

(a)

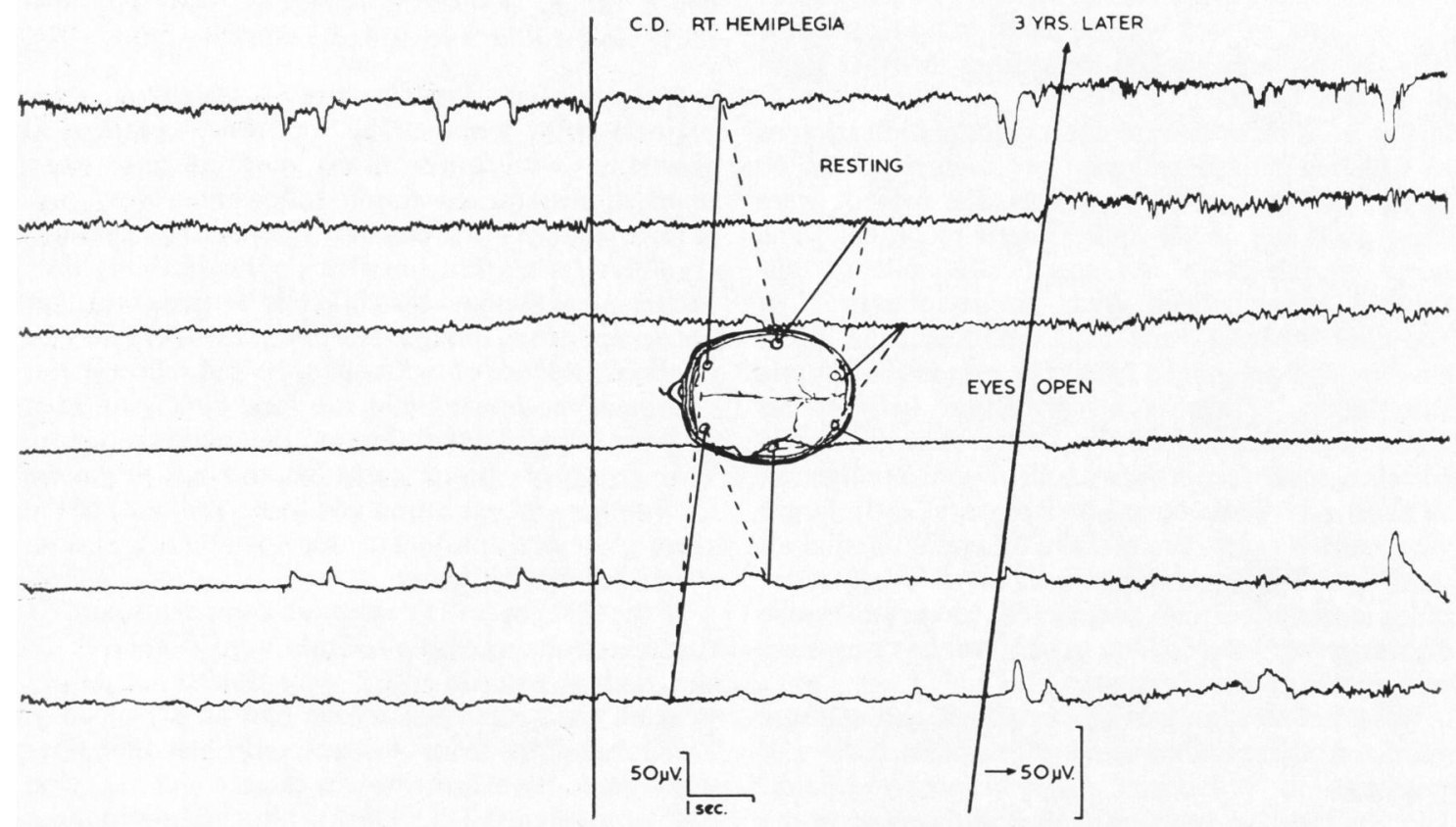

(b)

FIG. 2.-Two recordings of an epileptic girl with right hemiplegia. IQ 100, (a) Aged 10 years, during and after overbreathing, showing the silent area in the left central region. (b) Aged 13 years. During resting the silent area is still apparent. 
TABLE 4

ANALYSIS OF EEG RECORDS IN SPASTIC DIPLEGIA

\begin{tabular}{|c|c|c|c|c|c|c|c|c|c|}
\hline Aetiology & & $\begin{array}{l}\text { No. of } \\
\text { Patients }\end{array}$ & $\begin{array}{l}\text { No. of } \\
\text { Records }\end{array}$ & $\begin{array}{l}\text { No. of } \\
\text { Patients } \\
\text { With } \\
\text { Normal } \\
\text { Records }\end{array}$ & $\begin{array}{c}\text { Low } \\
\text { Voltage }\end{array}$ & $\begin{array}{c}\text { Mildly } \\
\text { Abnormal }\end{array}$ & Spikes & Epileptic & $\begin{array}{c}\text { No. } \\
\text { Ineducable }\end{array}$ \\
\hline $\begin{array}{lll}\begin{array}{l}\text { Prematurity: } \\
\text { Mild }\end{array} & \\
\text { Severe } & \ldots & \ldots \\
\text { Abnormal birth } & \ldots \\
\text { Genetic } & \ldots & \ldots \\
\text { No apparent } & \text { aetiology } \\
\text { Postnatal } & . & \ldots\end{array}$ & $\begin{array}{c}\ddot{.} \\
\ddot{*} \\
\cdots \\
\cdots\end{array}$ & $\begin{array}{r}24 \\
13 \\
14 \\
5 \\
3 \\
1\end{array}$ & $\begin{array}{r}34 \\
20 \\
31 \\
7 \\
5 \\
2\end{array}$ & $\begin{array}{r}13 \\
1 \\
0 \\
5 \\
2 \\
1\end{array}$ & $\begin{array}{l}0 \\
4\end{array}$ & $\begin{array}{l}2 \\
2 \\
4 \\
9\end{array}$ & $\begin{array}{r}5 \\
7 \\
10\end{array}$ & $\begin{array}{l}2 \\
5 \\
6\end{array}$ & $\begin{array}{r}2 \\
12 \\
8 \\
2 \\
1\end{array}$ \\
\hline & & 60 & 99 & 22 & 4 & 17 & 22 & 13 & 25 \\
\hline
\end{tabular}

records, 5 were of low intelligence, 2 coming within the ineducable range. Two with abnormal records had epilepsy, and one a severe behaviour disorder, necessitating institutional care, which may have been partially environmental. There were no low potential records.

In grade (2) 20 records were obtained from 13 patients. One was epileptic and ineducable.

The EEG findings were variable. One gave a normal record and this was a girl of above average intelligence who showed interesting visuo-perceptual difficulties. Four gave low potential or electrically quiet records. There were 7 children showing focal spikes and 5 of these had had one or more epileptic fits. The possibility of epilepsy occurring at any time is a serious factor in the prognosis of these children. In one boy who is educationally and physically making good progress, there is deterioration in the EEG records with a spike and wave focus reported for the first time in the left temporal region at 7 years. The significance of this has not yet been determined. The underlying pathology in this interesting group of symmetrical spasticity following a premature birth, with near normal intelligence, has not yet been determined. Abnormality in the EEG record does appear to be correlated with severity of handicap or the likelihood of epilepsy.

Diplegia Following Suspected Birth Trauma. A further 14 cases followed an abnormal birth, either slight prematurity, breech delivery, twin birth, or pre-eclampsia. In nearly every one there was mild to severe neonatal illness suggesting cerebral trauma. Four of them could be considered bilateral hemiplegias in that one side was more involved than the other and at least one arm was the most severely affected limb. The other 8 were diplegics and clinically similar to the premature group, though 2 were hydrocephalic.

All records were abnormal -4 mildly abnormal and 10 very abnormal and showing spikes. Of these
10, 5 were epileptic. Three showed low potential records. One microcephalic, ineducable epileptic girl gave repeated low voltage records. One showed a temporal lobe focus.

Seven of this group were severely mentally subnormal and one mildly subnormal. Yet two children with very abnormal EEG records attended Grammar Schools, and a gross error of judgement was made in one of them by giving a poor prognosis on the basis of an EEG finding.

Diplegia Following Other Causes. There remain 9 patients with varying aetiology: 5 were genetically determined and gave normal records; there were other affected sibs; only the lower limbs were involved.

One boy who had bilateral hemiplegia following a cerebral infection at the age of 1 month, gave two normal records after an interval of five years, suggesting that the cortex was little affected; his intelligence and insight were above normal and he was a stable, mature boy.

There were 3 patients in whom the clinical condition appeared identical with the previous group and yet the birth was full term and the evidence for genetic or perinatal causation was unconvincing. Two gave normal EEG records, one boy having an IQ of 117. One showed marked deterioration in the EEG records with occurrence of spikes and coinciding evidence of some physical and mental deterioration (Table 4).

Ataxias. A further group of cerebral-palsied children are classified as ataxics. They had a defect of balance and co-ordination, but it was not possible to be certain that the lesion was cerebellar in origin. Some showed considerable hypotonia, but a few were hypertonic and could be classified as ataxic diplegics. Two had nystagmus and several showed incoordinated eye movements. Four were epileptic and three ineducable. Of 19 children in this group 


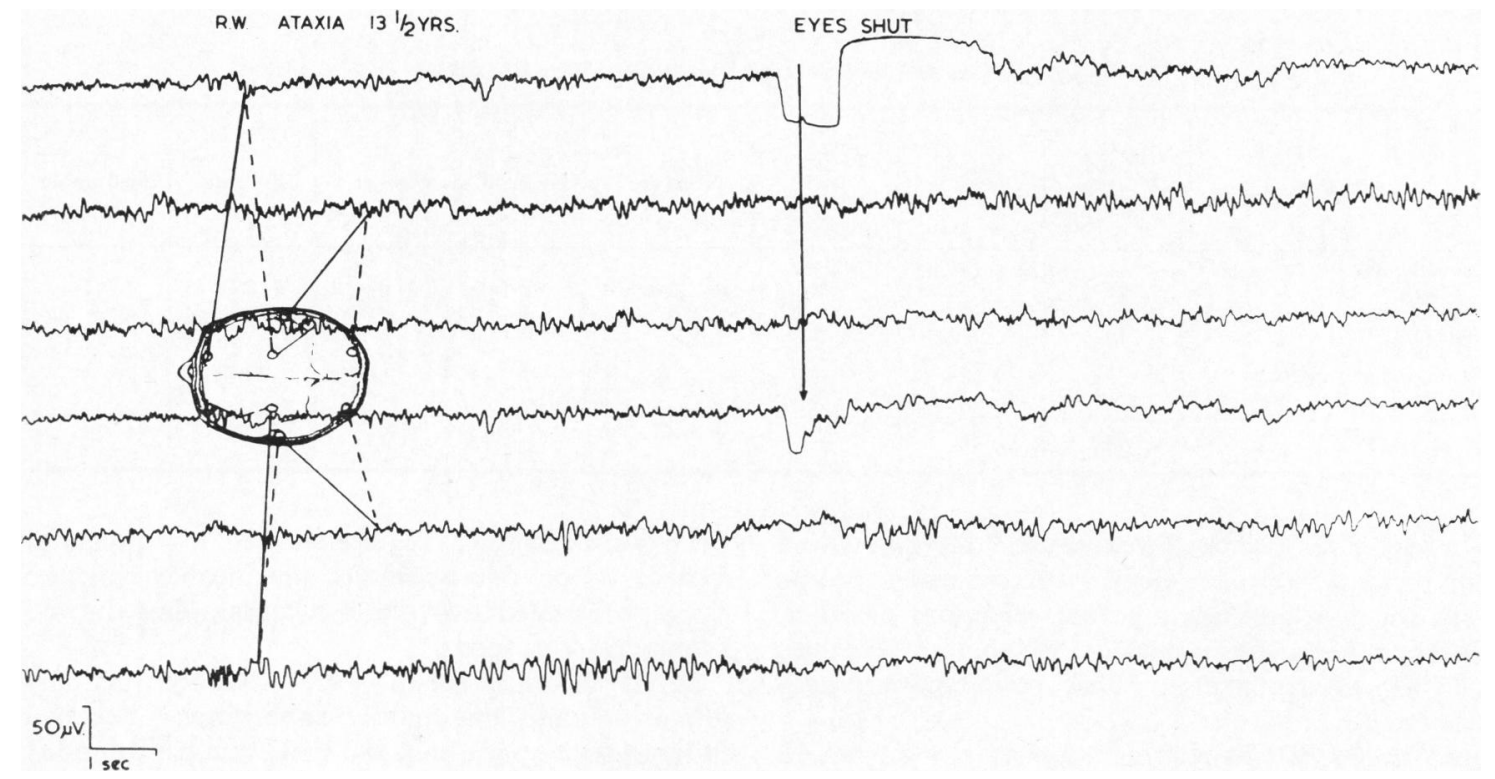

Fig. 3.--Recording of an ataxic patient aged $13 \frac{1}{2}$ years, showing diffuse theta activity and some delta mainly from the left central regions, unchanged when the eyes were closed.

from whom 36 EEG records were obtained, the aetiology was varied. Two followed measles encephalitis, were ineducable, and gave very abnormal records; 4 were premature and 6 followed a period of neonatal disorder suggesting cerebral trauma; 2 had arrested hydrocephalus. In 5 no apparent cause for the condition was found and all may have been developmental in origin, though one hypotonic child appeared to be deteriorating and had been called psychotic.

As in the group described by Ounsted, the EEG findings varied, but all but four of the records were abnormal. One measles encephalitic child and one presumed post-encephalitic child gave low potential records. Four showed spikes and two of these were epileptic. Eight showed the slow waves in the occipital or occipito-temporal regions, reported by Lesny. Photic stimulation caused no alteration in the slow waves in some patients, and in one patient, eye opening suppressed the waves. These records from 8 patients appeared to be of a different nature from other records in cerebral palsy and may represent a distinct group of cases with dysplasia of the cerebellum. Lesny's cases were confirmed by an air-encephalography which was not performed in this series (Fig. 3).

Minimal Movement Defect. A number of patients were referred to the clinic with minimal movement defect. There was often evidence of other neurological deficit. Many had been referred through school medical officers, as a child's total handicap became obvious when seen with a group of normal children. The movement defects were such conditions as a mild generalized spasticity, athetosis, monoplegia, or general incoordination. There was often an abnormal reflex pattern such as increased arm and leg jerks and extensor plantar responses. The majority had an additional handicap. Of 24 patients, 13 were of below average intelligence, 4 were epileptic, and 5 had a speech defect, a dysarthria or dysphasia. In a number of patients there was a clear history of perinatal or postnatal illness. In some cases there remained a doubt whether the total defect was organic in origin or emotionally or environmentally determined. An EEG record was additional evidence of underlying brain pathology. Forty records were obtained.

In 4 patients the EEG was normal. All had minimal spasticity and attended school. One had an aphasic element.

The remaining 20 children showed varying degrees of abnormality. Two had electrically quiet records: both had been premature babies and the movement defect suggested minimal athetosis. Five showed immature records for the child's age. There were 13 records that were more abnormal, showing focal or diffuse delta and theta rhythm and, in one case, alphoid rhythm. Seven records revealed spikes and in four of these the children were epileptic.

These very abnormal records emphasized the fact 
that this rather indefinite group of patients contained children with considerable brain disease.

\section{Discussion}

From these findings it cannot be suggested that the EEG records give a firm indication of the severity of the physical handicap, the occurrence of epilepsy, or the level of intelligence. But after a full clinical appraisal of the child the EEG has some confirmatory and prognostic value.

A normal record appeared to be related to a mild degree of physical handicap. It occurred in 7 out of 9 cases of mild athetosis, and in only 1 out of 14 with severe athetosis. Similarly, a normal record was obtained in 18 out of 19 diplegics with involvement of legs only, and in 4 out of 28 where all 4 limbs were involved. Normal records were obtained in the genetically determined cases.

Normal records were obtained in only two children who suffered from epilepsy. One was a young hemiplegic boy and the other an athetoid girl, where the mother's history of petit mal attacks may have been misleading. In all types of movement defect the EEG records did not give an indication of the occurrence of epilepsy, but the more abnormal the record the more likely was the incidence of epilepsy. Fits were occurring in patients who, though giving abnormal records, did not show typical spike or wave and spike discharges; and vice versa, epilepsy up to 10 years did not occur in children who gave a record strongly suggestive of epilepsy. The value of these records was the indication they gave that epilepsy might occur and that the patient should be carefully watched and followed up.

The EEG records appeared to be a poorer indication of intelligence rating than of degree of physical handicap or occurrence of epilepsy. An abnormal record frequently did not indicate poor intelligence and vice versa.

The records did not tend to change to any significant degree over the years, which suggests the static nature of the lesions. In 1 athetoid, 5 hemiplegics, and 1 quadriplegic, there were deteriorating records, and in all but the last patient there was accompanying clinical evidence of deterioration.
Of particular interest is the incidence of low voltage and electrically silent records. This finding occurred in all groups but particularly in cases of severe athetosis.

On several occasions a request was made for an EEG due to a severe behaviour disorder in the child. Many of these children show aggressive behaviour and temper tantrums during periods of stress. This has been particularly noted when a younger sib has commenced to walk and overtaken the handicapped patient. In some cases the disturbance has been so severe as to suggest epilepsy, but in no case has there been a change in the EEG recording.

\section{Summary}

The results are recorded of 382 electroencephalograms in 206 cerebral-palsied children. The findings have been classified under headings which indicate the movement handicap, athetosis, hemiplegia, diplegia, ataxia, and minimal movement defect.

My thanks are due to Mrs. V. Aldridge who carried out the majority of the EEG recordings. I am also grateful to Professor A. V. Neale under whose direction the work has been carried out, and for the facilities for EEG recording at the Bristol Children's Hospital, which made the task of testing these handicapped children so much easier.

\section{REFERENCES}

Aird, R. B., and Cohen, P. (1950). Electroencephalography in cerebral palsy. J. Pediat., 37, 448.

Denhoff, E., and Robinault, I. P. (1960). Cerebral Palsy and Related Disorders. McGraw, New York.

Jabbour, J. T., and Lundervold, A. (1963). Hemiplegia: a clinical and electroencephalographic study in childhood. Develop. Med. Child Neurol., 5, 24.

Lesny, I. (1963). E.E.G. in cerebellar disease. Little Club Clin. dev. Med., 8, 91.

Lundervold, A. (1960). E.E.G. in cerebral palsy. Cerebr. Palsy Bull., $2,82$.

Melin, K. A. (1962). E.E.G. and epilepsy in cerebral palsy. Develop. Med. Child Neurol., 4, 180.

Ounsted, C. (1963). E.E.G. anomalies associated with benign congenital cerebellar dysplasia in childhood. Little Club Clin. dev. Med., $8,93$.

Pampiglione, G. (1958). Electroencephalography in cerebral palsy. Cerebr. Palsy Bull., 1(3), 16.

Perlstein, M. A., Gibbs, E. L., and Gibbs, F. A. (1946). The electroencephalogram in infantile cerebral palsy. Res. Ass. nerv. ment. Dis. Publ., 26, 377.

Woods, G. E. (1963). Some observations on 141 cases of infantile hemiplegia. Cerebr. Palsy Rev., 24, 11. 